\title{
Synthesis of polycationic bentonite-ionene complexes and their benzene adsorption capacity
}

\author{
Valquíria Campos ${ }^{1}$ and Celize Maia Tcacenco ${ }^{2}$ \\ 'Universidade Estadual Paulista "Júlio de Mesquita Filho" - UNESP, \\ Campus de Sorocaba, Sorocaba, SP, Brasil \\ ${ }^{2}$ Centro Universitário FIEO - UNIFIEO, Osasco, SP, Brasil \\ *vcampos@sorocaba.unesp.br
}

\begin{abstract}
The purpose of this work was to structurally modify clays in order to incorporate water-insoluble molecules, such as petroleum hydrocarbons. The potential for ion exchange of quaternary ammonium salts was studied, which revealed their ability to interact with anions on the cationic surface, for environmental applications of the material. Ionenes, also known as polycations, have many potential uses in environmental applications. In this work, cationic aliphatic ammonium polyionenes, specifically 3,6-ionene and 3,6-dodecylionene, were prepared for incorporation into clay to form bentonite-ionene complexes. The intercalation of bentonite with ionene polymers resulted in an increase in the basal spacing of 3,6-dodecylionene from 1.5-3.5 $\mathrm{nm}$. The higher d001 spacing of 3,6-dodecylionene samples than that of 3,6-ionene samples may be attributed to their longer tail length. The behavior of the TG/DTG curves and the activation energy values suggest that 3,6-dodecylionene $\left(E=174.85 \mathrm{~kJ} \mathrm{~mol}^{-1}\right)$ is thermally more stable than 3,6 ionene $\left(\mathrm{E}=115.52 \mathrm{~kJ} \mathrm{~mol}^{-1}\right)$ complexes. The adsorption of benzene by 3,6-ionene and 3,6-dodecylionene was also investigated. The increase in benzene concentrations resulted in increased benzene adsorption by the sorbents tested in this work. The sorption capacity of benzene on ionene-modified bentonite was in the order of 3,6-dodecylionene $>3,6$-ionene.
\end{abstract}

Keywords: 3,6-ionene, 3,6-dodecylionene, synthesis, adsorption of benzene.

\section{Introduction}

In 1968, Rembaum et al. ${ }^{[1]}$ adopted the name "ionene" for polymers that contain ionic groups derived from amino containing monomers. The polymerization process typically resulted in a variety of cyclic species, in addition to the polymer product. The nomenclature of aliphatic, non-segmented ionenes is associated with the number of methylene units from the monomers, namely ditertiary amines and alkyl dihalides, respectively, i.e., $\mathrm{x}, \mathrm{y}$-ionene, where $\mathrm{x}=$ number of $\mathrm{CH}_{2}$ units in the diamine and $\mathrm{y}=$ number of $\mathrm{CH}_{2}$ units in the dihalide.

The name bentonite derives from the location of the first commercial deposit of plastic clay in the United States. This clay has the property of increasing several times its original volume in the presence of moisture. In 1897, Knight reported that, since 1888, William Taylor had been marketing a unique type of clay found in Fort Benton, Wyoming, and proposed the name taylorite, but later suggested "bentonite," since the first name was already in use ${ }^{[2]}$. Bentonite can be defined as a rock composed essentially of a montmorillonite clay mineral formed by devitrification and subsequent chemical alteration of a glassy material of igneous origin, usually a volcanic tuff or ash in alkaline environments with restricted movement of water ${ }^{[3]}$. Montmorillonite is the most abundant clay mineral of the smectite group, whose general chemical formula is given by $\mathrm{M}_{\mathrm{x}}\left(\mathrm{Al}_{4-\mathrm{x}} \mathrm{Mg}_{\mathrm{x}}\right) \mathrm{Si}_{8} \mathrm{O}_{20}(\mathrm{OH})_{4}$. It belongs to the group of 2:1 phyllosilicates, whose plates are characterized by structures consisting of two tetrahedral silicon sheets with a central octahedral alumina sheet, which are joined together by oxygen atoms that are common to both sheets. The sheets are continuous in the directions of the $\boldsymbol{a}$ and $\boldsymbol{b}$ axes and generally have a parallel orientation on the planes (001) of crystals, which gives it its laminated structure $^{[4]}$. Montmorillonite plates, which are very fine, exhibit an irregular profile with a tendency to aggregate in the drying process, and show good delamination ability when placed in contact with water. The stacking of these plates is governed by relatively weak polar forces and by van der Waals forces. These plates are separated by gaps called galleries or interlamellar layers, which contain electrostatically fixed exchangeable cations such as $\mathrm{Na}^{+}$, $\mathrm{Ca}^{2+}$, and $\mathrm{Li}^{+}$. The function of these cations is to compensate negative charges generated by isomorphic substitutions that occur in the crystal lattice, such as $\mathrm{Al}^{3+}$ by $\mathrm{Mg}^{2+}$ or $\mathrm{Fe}^{2+}$, or $\mathrm{Mg}^{2+}$ by $\mathrm{Li}^{+}$. About $80 \%$ of the exchangeable cations in montmorillonite are contained in the galleries and $20 \%$ on the lateral surfaces ${ }^{[4]}$. In the presence of water, $\mathrm{Na}^{+}$and $\mathrm{Ca}^{2+}$ exist as hydrates and the clay surface is hydrophilic.

Therefore, natural bentonite is an ineffective adsorbent for the non-polar, non-ionic organic compounds in water. The surface properties of natural bentonite can be greatly modified with large organic surfactants such as long chain quaternary alkyl ammonium salts by simple ion-exchange reactions. As a result, the organobentonite obtained becomes a more effective adsorbent for the removal of poorly watersoluble organic pollutants from wastewater ${ }^{[5-12]}$.

In this work, ammonium ionenes were mixed with bentonite clay, which offers many advantages over the conventional materials used for removing organic pollutants 
from water. Among the various engine fuels used in Brazil, gasoline is the one that causes the gravest concerns with regard to groundwater contamination because of its high concentration of BTEX (benzene, toluene, ethylbenzene, and xylenes), which are the most water-soluble constituents of gasoline and have the highest potential for migration into groundwater ${ }^{[13-15]}$. Benzene is the most toxic component of the group because it is a carcinogenic substance and acute exposure to it may be lethal.

In this study, natural bentonite was modified with polybrene and a new polybrene polycation derivative called 3,6-dodecyl was obtained. Benzene adsorption was investigated after the characterization of the ionene-modified bentonites (3,6-ionene and 3,6-dodecylionene).

\section{Materials and Methods}

The bentonite used as starting material to obtain the ionenes was BFN (a national processed bentonite) supplied by the company BF-Clay Especialidades Ltda, located in São Paulo, Brazil. This commercial bentonite is subjected to a previous treatment for the insertion of sodium ions and has a $\mathrm{CEC}$ of $102.7 \mathrm{cmol} \mathrm{kg}^{-1}$.

The ammonium salts used in this study were hexadimethrine bromide (polybrene or 3,6-ionene) was supplied by SigmaAldrich for the synthesis of 3,6-ionene and dodecyl bromide for a new experimental series. The water used in all the stages of preparation, in washing and in the preparation of standard solutions was purified in a Millipore Milli-Q system. According to the information on the polybrene fact sheet, 3,6-ionene has a molecular weight of $1122.6 \mathrm{~g}$ $\mathrm{mol}^{-1}$, which leads to a degree of polymerization equal to three. The entire process was carried out very carefully as 3,6-ionene is highly hygroscopic. The polymer was weighed rapidly, and its container was immediately closed and placed in a desiccator. The reagents and solvents involved in the synthesis (ethanolamine and acetonitrile) were previously distilled and dried to eliminate water, whose presence would compromise synthesis' results. The ionene-bentonite complexes were centrifuged, filtered repeatedly for several days to ensure the complete elimination of water, and then oven-dried at $60{ }^{\circ} \mathrm{C}$ for $30 \mathrm{~h}$. They were then macerated, placed in stoppered flasks, and stored in a desiccator.

The ionenes were characterized structurally by hydrogen nuclear magnetic resonance ( $\left.{ }^{1} \mathrm{H}-\mathrm{NMR}\right)$, in $\mathrm{CDCl}_{3}$, using a Bruker DPX-300NMR spectrometer operating at a frequency of $300 \mathrm{MHz}$. The NMR ${ }^{1} \mathrm{H}$ spectra for both polymers were in agreement with the proposed structure. To examine the changes in the clay mineral in response to the treatment with ionenes, the bentonite and the Bt-ionene complexes were characterized to verify their composition, basal spacing, morphology and thermal stability. Chemical compositions were determined by X-ray fluorescence using a Phillips PW2404 XRF spectrometer. The fluorescence measurements were taken with a Hitachi F4500 fluorometer. The fluorescence spectrum of ANSA was obtained in $1.32 \mathrm{mM}$ with excitation at $376 \mathrm{~nm}$.

The percentage of carbon, hydrogen and nitrogen in the bentonites modified with ionenes was determined by elemental analysis $(\mathrm{CHN})$. Fourier transform infrared spectroscopy was performed in a Perkin Elmer Spectrum One FTIR with a resolution of $4 \mathrm{~cm}^{-1}$, in the range of $4000-450 \mathrm{~cm}^{-1}$.

Basal spacings were determined by X-ray diffraction (XRD) analysis in a Siemens D5000 diffractometer using $\mathrm{CuK} \alpha$ radiation $(\lambda=0.15416 \mathrm{~nm})$ and applying $0.0282 \mathrm{~h}$ steps at $1.0 \mathrm{~s} / \mathrm{step}$. The raw material, BFN bentonite, consists of $\mathrm{Na}$-smectite with quartz and feldspar. The air-dried products were also characterized by XRD to verify the intercalation of polycations between the clay interlayers. The values of the basal spacings $\left(d_{001} / \mathrm{nm}\right)$ were determined using Bragg's equation.

The starting and modified samples were mounted on metal stub holders and coated with gold. The specimens obtained by two synthesis routes were then subjected to electron detection in a LEO 440i SEM coupled to an Oxford $\mathrm{Si}(\mathrm{Li}) \mathrm{X}$-ray Energy Dispersive Spectrometer.

The samples were degraded in a TA Instruments Q50 thermogravimetric analyzer (TGA 50) in nitrogen atmosphere. Non-isothermal experiments were performed in the temperature range of $10-1050{ }^{\circ} \mathrm{C}$, applying different heating rates $(10$, 15 and $20^{\circ} \mathrm{C} \mathrm{min}^{-1}$ ) for each sample. The nitrogen flow was maintained at $50 \mathrm{~cm}^{3} \mathrm{~min}^{-1}$ and samples of about $12 \mathrm{mg}$ were used in all the experiments. The thermogravimetric data were analyzed by the Kissinger method ${ }^{[16]}$, and parameters such as the apparent activation energy were determined using the TGA-50 software. The apparent activation energy was derived from the slope of the dependence of the heating rate upon the reciprocal absolute temperature, at a defined mass loss. The polymers were analyzed thermogravimetrically after oven-drying them at $60{ }^{\circ} \mathrm{C}$.

The equilibrium batch sorption experiment of benzene on the bentonite-ionenes, including 3,6-ionene and 3,6-dodecylionene, was performed by placing $1 \mathrm{~g}$ of sample in a vial and adding $50 \mathrm{~mL}$ of a definite concentration of benzene solution. The benzene concentrations varied from 0.084 to $1.27 \mathrm{mmol} \mathrm{L}^{-1}$. The samples were placed in flasks with lids, taking care to prevent the formation of headspace. These suspensions were agitated for $24 \mathrm{~h}$ on a reciprocating shaker, after which the suspensions were centrifuged and the extracted solution was analyzed to determine the benzene concentration. The benzene concentration in the resulting solution was determined by gas chromatography (GC/MS Agilent 5975C with ALS 7693). Because the solubility of benzene is lower at high concentrations in solution (the solubility of benzene in water at $20^{\circ} \mathrm{C}$ is $0.188 \%$ ), ethanol aliquots were added to the benzene and organophilic clay solutions until the maximum concentration of ethanol in the system did not exceed $20 \%{ }^{[17]}$.

\section{Synthesis}

The organophilic bentonites were prepared considering that the 3,6-ionene and 3,6-ionene dodecyl monomers have two cationic sites and that each ionene monomer would be bound to two cationic sites in the clay mineral. The cation exchange capacity of BFN is $102.7 \mathrm{cmol}$ of cations $/ 100 \mathrm{~g}$ of clay. Therefore, $55 \mathrm{mmol}$ of monomers $/ 100 \mathrm{~g}$ of BFN would be necessary for the exchange to take place in all the sites by quaternary ammonium groups. The ionene 
structures were confirmed by hydrogen nuclear magnetic resonance ( $\left.{ }^{1} \mathrm{H}-\mathrm{NMR}\right)$.

\subsection{Synthesis and derivatization of 3,6-ammonium ionene}

The bentonite-ionene complexes were prepared with $5.0 \mathrm{~g}$ of bentonite. The clay was delaminated in $250 \mathrm{~mL}$ of deionized water, under agitation at room temperature. After 60 minutes of agitation, an aqueous solution of 3,6-ionene was added and the mixture was shaken for $48 \mathrm{~h}$. The resulting mixture was transferred to a lidded test tube and allowed to equilibrate for 24 hours. The mixture was then vacuum-filtered and washed with deionized water until, after the addition of a solution of $\mathrm{AgNO}_{3}$, no more bromide ions were detected. It was then washed with commercial ethanol and dried at $60{ }^{\circ} \mathrm{C}$ for 48 hours. The dry material was ground in a mortar and sifted through 200 mesh sieves $(\mathrm{D}=74 \mu \mathrm{m})$. To verify the changes in the clay mineral after the treatment with ionenes, the Bt-ionene complexes were characterized to ascertain their composition, morphology, thermal stability and basal spacing.

\subsubsection{Demethylation of 3,6-ionene}

Three $\mathrm{g}$ ( $8 \mathrm{mmol}$, considering the monomer) of hexadimethrine bromide and $12 \mathrm{~mL}$ of distilled ethanolamine were placed in a reaction flask. The system was kept under reflux for four hours at $165{ }^{\circ} \mathrm{C}$. At the end of this reflux period, $10 \mathrm{~mL}$ of distilled water were added, after which the polyamine was extracted using three portions of washed, dried and distilled chloroform. After separation of the organic phase and successive washes with water, the organic phase was dried with anhydrous sodium sulfate and the chloroform was eliminated by rotary evaporation. The mass of polyamine obtained from 3,6-ionene was $2.4165 \mathrm{~g}$, with a reaction yield of $80.55 \%$. The resulting product was a viscous yellow liquid with the characteristic odor of amine. The preparation of the polyamine derived from 3,6-ionene is illustrated in Scheme 1.

The 3,6-polyamine was also identified by ${ }^{1} \mathrm{H}-\mathrm{NMR}$ $(300 \mathrm{MHz})$ in $\mathrm{CDCl}_{3}$. In these spectra, the signal of the hydrogen atoms of the two methyl groups attached to each quaternary amino group in the ionene $\delta=3.5$ is absent, and there is a signal of the protons of the methyl group connected to a tertiary amino group $\delta=2.2^{[18]}$.
3.1.2. Quaternization of tertiary polyamine derived from 3,6-ionene with bromododecane

Twenty $\mathrm{mL}$ of distilled acetonitrile and $15 \mathrm{mmol}$ of 1-bromododecane were added to a flask containing $12 \mathrm{mmol}$ of tertiary polyamine derived from 3,6-ionene. The flask was kept under reflux at $70^{\circ} \mathrm{C}$ for 30 hours under magnetic shaking and the solvent was eliminated by rotary evaporation, with a reaction yield of $82 \%$.

\subsection{Synthesis of 3,6-dodecylionene}

The bentonite-ionene complexes were prepared with $5.0 \mathrm{~g}$ of bentonite. This concentration was chosen to prepare a bentonite-ionene complex with $1 \%$ of ionene. This concentration of $1 \%$ was chosen because we were interested in comparing the incorporation of the two hydrophobically distinct polymers, 3,6-ionene and 3,6-dodecyl ionene, in bentonite using the same parameters, since 3,6-dodecyl ionene is much less water-soluble.

The clay was delaminated in $250 \mathrm{~mL}$ of deionized water, under agitation at room temperature. After 60 minutes of agitation, an aqueous solution of 3,6-ionene was added and the mixture was shaken for $48 \mathrm{~h}$. The resulting mixture was transferred to a lidded test tube and allowed to equilibrate for 24 hours. The mixture was then vacuum-filtered and washed with deionized water until, after the addition of a solution of $\mathrm{AgNO}_{3}$, no more bromide ions were detected. It was then washed with commercial ethanol and dried at $60{ }^{\circ} \mathrm{C}$ for 48 hours. The dry material was ground in a mortar and sifted through ABNT $n^{\circ} 200$ mesh sieves $(D=74 \mu \mathrm{m})$. The synthesis of 3,6-dodecylionene yielded $78.6 \%$ of a greenish-white product.

Requaternization was performed by the reaction with bromododecane for the preparation of the 3,6-ionene dodecyl (Scheme 2), which was also identified by ${ }^{1} \mathrm{H}-\mathrm{NMR}$ $(300 \mathrm{MHz})$ in deuterated methanol and presented chemical displacements, in ppm relative to TMS, of: $\delta=0.86(6 \mathrm{H}, \mathrm{H}$ of the methyl groups of the $n$-dodecyl chain), $\delta=1.25(36 \mathrm{H}$, $2 \mathrm{H}$ inside the long-segment methylene and $32 \mathrm{H}$ inside the $n$-dodecyl chain), $\delta=1.36(4 \mathrm{H}$, outside the methylene segment of the $n$-dodecyl chain), $\delta=1.75\left(8 \mathrm{H}, \mathrm{H}_{\beta}\right), \delta=2.17$ $\left(2 \mathrm{H}\right.$, central $\mathrm{H}$ of the trimethylene segment, $\left.\mathrm{H}_{\mathrm{c}}\right), \delta=3.07(6 \mathrm{H}$, $\mathrm{H}$ of the $\mathrm{CH}_{3}$ groups bound to quaternary nitrogen), and $\delta=3.34\left(12 \mathrm{H}\right.$, methylene, bound to quaternary nitrogen, $\left.\mathrm{H}_{\alpha}\right)$.

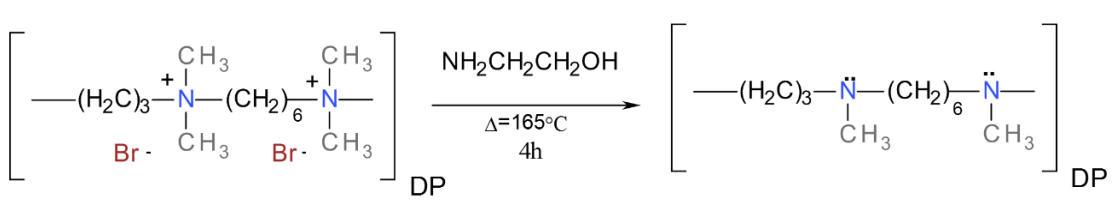

Scheme 1. Dequaternization or monodemethylation of 3,6-ionene $(y=6)$ using the ethanolamine nucleophile. DP= degree polymerization.

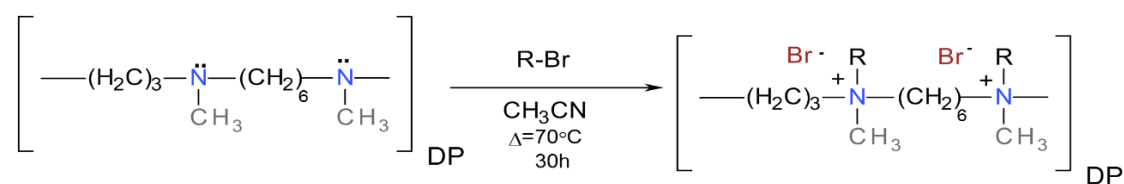

Scheme 2. Requaternization of tertiary polyamine derived from 3,6-ionene $(y=6)$ for the preparation of 3,6-dodecylionene $\mathrm{R}=-\left(\mathrm{CH}_{2}\right)_{11} \mathrm{CH}_{3}$ and $\mathrm{DP}=$ degree polymerization and $\mathrm{R}=$ dodecyl. 


\section{Results and Discussion}

In 3,6-ionene, 3 and 6 correspond to the numbers of $\mathrm{CH}_{2}$ groups between the nitrogen atoms, that are associated with the aliphatic parts of the dibromide and the diamine (Figure 1), respectively. Small organic cations (tetramethylammonium) generate relatively rigid non-polar surfaces which are responsible for the removal of non-ionic solutes through adsorption. Larger organic cations (hexadecyltrimethylammonium) adsorbed on clay generate an organic partition medium through the agglomeration of its flexible alkyl chains. When a polycation is added to a clay surface, the contact between it and the surface causes the configuration of each polymer chain to take on several "train" segments in close contact with the surface, alternating with "loops" and producing "tails" at the chain ends, which are not adsorbed (Figure 2). Earlier fluorescence studies indicate this type of model ${ }^{[19,20]}$. Ionenes without tails (long hydrocarbon chain) cannot incorporate non-polar hydrophobic molecules such as pyrene. In aqueous solution, these molecules were exposed to the polar medium, while in a medium containing modified ionenes such as $3, y$-dodecylionene, the pyrene remained in a hydrophobic medium. This behavior indicated the formation of loops with hydrophobic "tails," protecting pyrene from aqueous medium. The interaction between the polycation and the clay surface takes place through Coulombic interactions between the positively charged sites in the polymer and the negatively charged clay surface ${ }^{[21]}$.

\subsection{CHN analysis}

The data of the elemental analysis confirm that the 3,6-dodecylionene composites $(14.77 \%)$ contain the more percentages of carbon, hydrogen and nitrogen than 3,6-ionene $(10.10 \%)$. Considering that the quantity of ionene in the synthesis was calculated from the CEC of the bentonite, it can be stated that the incorporation was practically equivalent for BFN. Both polymers analyzed satisfactorily $(\mathrm{CHN})$ assuming between one and two residual waters of hydration per quaternary ammonium.

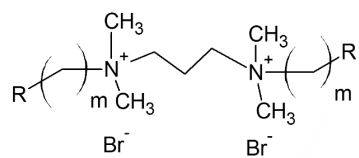

Figure 1. Structure of $[3, \mathrm{~m}]$-ionene bromide $(\mathrm{m}=6)$ used in a bentonite incorporation.

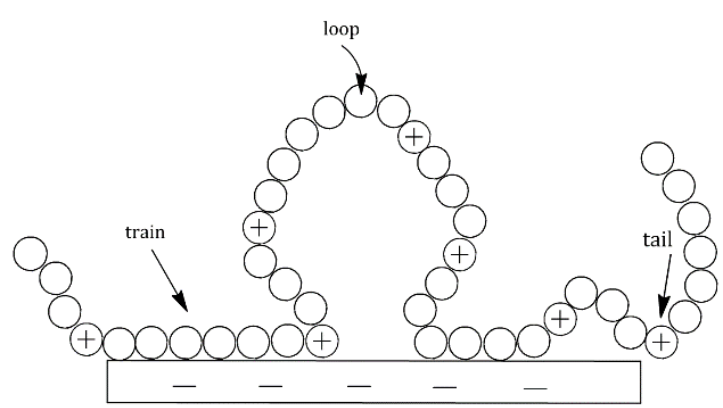

Figure 2. Conformational elements of a polycation chain adsorbed on a clay surface: 3,6-ionene (modified from Costa Filho et al. ${ }^{[22]}$.

\subsection{Chemical composition analyzed by XRF}

The efficiency of the cationic exchange was verified from the X-ray fluorescence analysis, which provided semi-quantitative data of the elemental composition of the bentonite and of the ionene complexes (Table 1). In each case, it was found that the addition of polymer solutions to the clay suspensions led to a significant carbon content in the resulting complexes. The high degree of incorporation of ionenes was confirmed by the reduction in the sodium and calcium content in the sodium bentonite, indicating its removal from the polycations. Because it is sodium clay, the average percentage of $\mathrm{Na}^{+}$ions exchanged was higher, indicating that these polymers have a strong affinity for bentonite, independently of the spacer size and molar mass of the polycations. All of the polycations reacted to form interlayer complexes with a clay, which displaced more $\mathrm{Na}^{+}$ and little $\mathrm{Ca}^{2+}$. In addition, bromide counterions associated to the quaternary ammonium groups non-adsorbed on the clay surface, probably localized in segments of loops or tails in the polycation chain, confirming that the cationic exchange was also satisfactory in these systems. It is known from the literature that polymers with structural characteristics similar to those of ionenes adsorb intensely on sodium clays ${ }^{[23]}$.

\subsection{X-ray diffraction}

The values of the basal spacings reflect the mode of adsorption of the polymer. The peaks shifted to lower $2 \Theta$ angle $\left(^{\circ}\right)$ values as the $\mathrm{BFN}$-ionene spacer size increased, indicating an increase in the distance of the clay interlayers. Costa Filho et al. ${ }^{[22]}$ demonstrates that the adsorption of these ionenes did not affect the molar mass but influenced the charge density in the polymer chain, i.e., the lower the charge density, the more "loops" are formed and the higher the basal expansion observed between the clay's layers. Although all these polycations are $100 \%$ cationic, the 3,6-dodecylionene showed higher basal spacing $\left(d_{001}=3.5 \mathrm{~nm}\right)$. The greater distance between the centers of charge was reflected in the larger number of "loops" and "tails" not adsorbed along the clay's surface, causing its layers, which originally showed $d_{001}=1.5 \mathrm{~nm}$ to expand. These data indicate that it is possible to produce ionene-modified bentonites whose basal spacings can be altered as a function of the internal adsorption of these linear polycations, varying the size of their paraffinic spacers, and hence, their charge densities. The X-ray diffraction data of the 3,6-ionene demonstrated that the incorporation pattern was similar, indicating the interlamellar insertion of the ionene. The high degree of incorporation of the ionenes was confirmed by the reduction in the sodium and calcium contents of the bentonite, indicating their removal by the polycations.

\subsection{SEM}

Figure 3a illustrates the starting bentonite, while Figures $3 \mathrm{~b}$ and $\mathrm{c}$ depict the morphology of the polymer microstructures. The 3,6-ionene sample presented a heterogeneous morphology, suggesting the existence of two phases: one in high relief, with the presence of scales, interspersed by a smooth phase, in low relief. The presence of scales is clearly visible and highly uniform in the 3,6-dodecylionene sample. The scanning electron microscopy results revealed that the synthesis 
Campos, V., \& Tcacenco, C. M.

Table 1. Chemical compositions determined by X-ray fluorescence analysis (mass/ \%)

\begin{tabular}{lcccccccccccc}
\hline \multicolumn{1}{c}{ Sample } & $\mathbf{S i O}_{2}$ & $\mathbf{A l}_{2} \mathbf{O}_{3}$ & $\mathbf{M n O}$ & $\mathbf{M g O}$ & $\mathbf{C a O}$ & $\mathbf{N a}_{2} \mathbf{O}$ & $\mathbf{K}_{2} \mathbf{O}$ & $\mathbf{T i O}_{2}$ & $\mathbf{F e}_{2} \mathbf{O}_{3}$ & $\mathbf{P}_{2} \mathbf{O}_{5}$ & $\mathbf{L O I}^{*}$ & $\mathbf{B r}$ \\
\hline BFN & 62.35 & 19.07 & 0.03 & 3.44 & 0.73 & 3.20 & 0.27 & 0.18 & 4.21 & 0.05 & 5.97 & n.d. \\
3,6-ionene & 61.47 & 18.86 & 0.03 & 3.14 & 0.29 & 0.17 & 0.25 & 0.20 & 4.17 & 0.05 & 9.68 & 2.03 \\
3,6-dodecyl & 61.33 & 18.78 & 0.04 & 3.11 & 0.22 & 0.09 & 0.23 & 0.19 & 4.19 & 0.04 & 9.02 & 2.17 \\
\hline
\end{tabular}

*Loss of ignition.
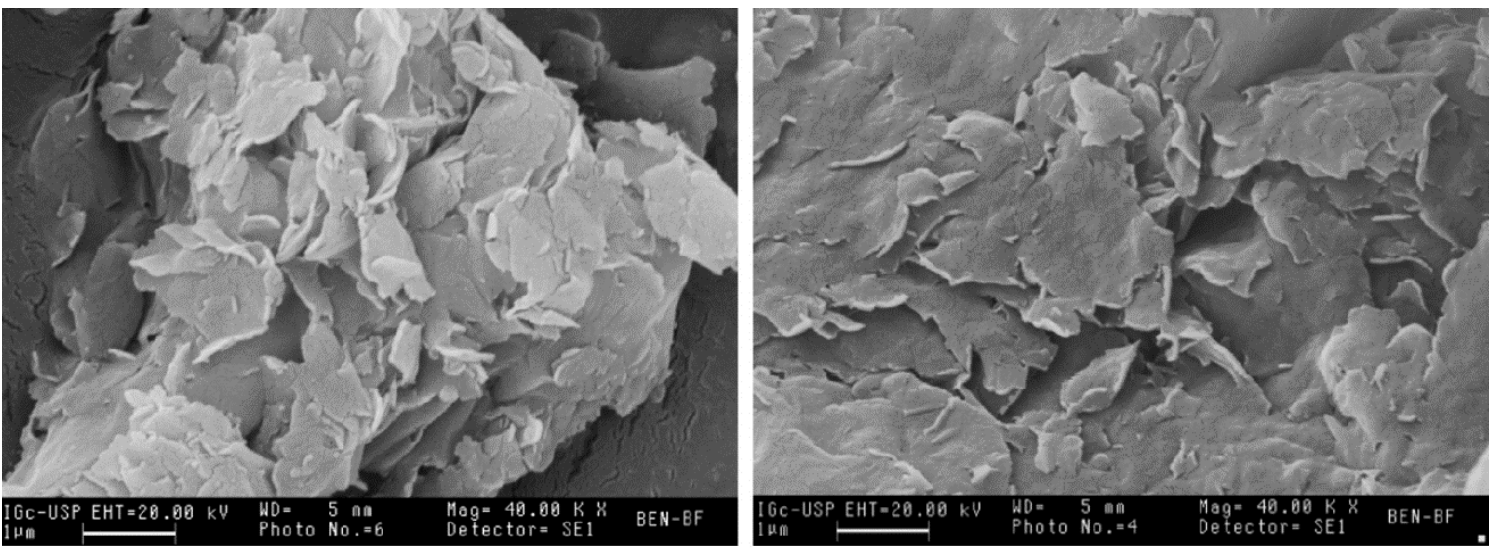

(a)
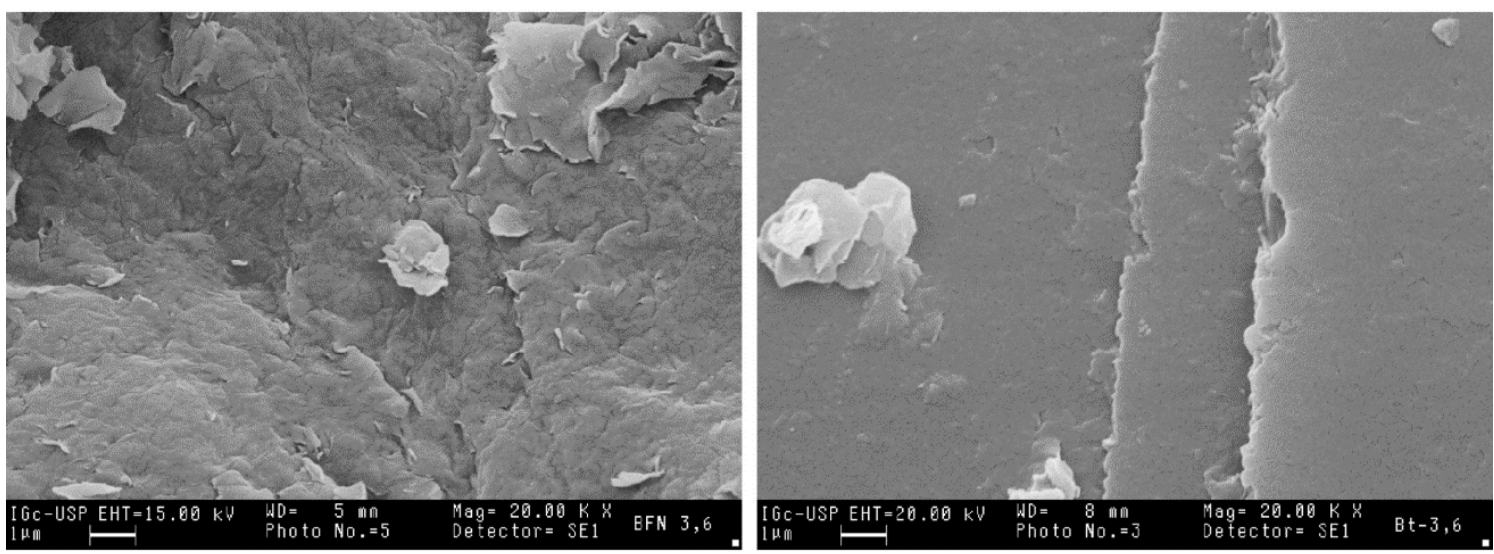

(b)
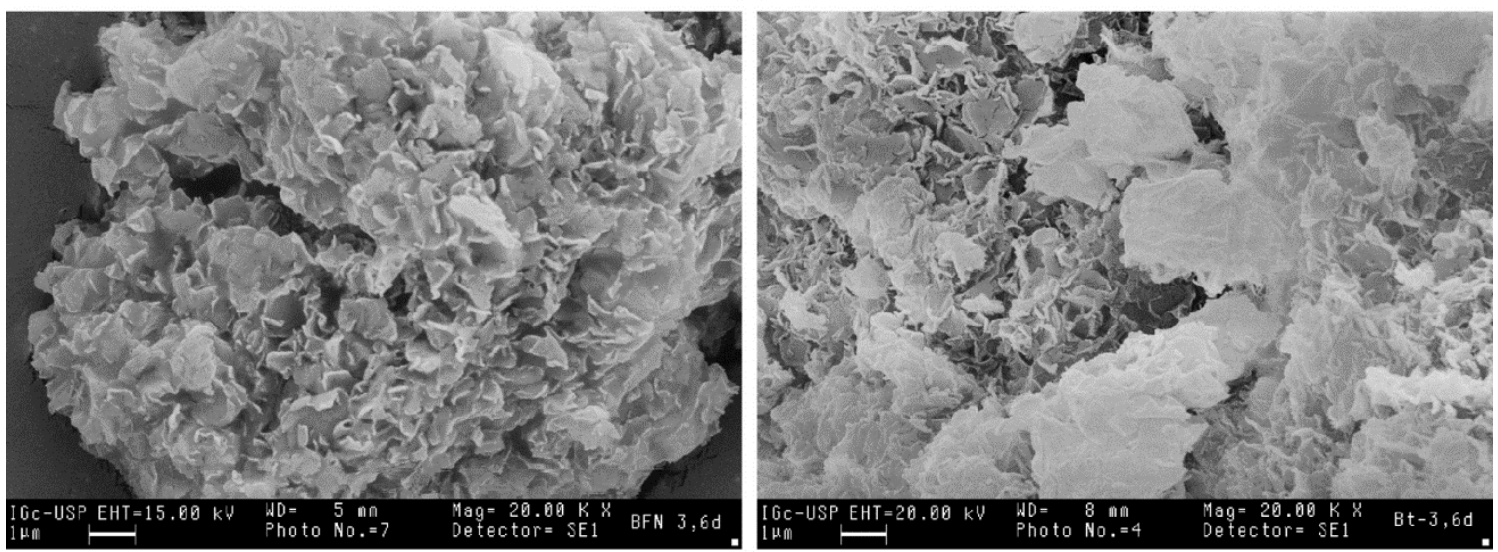

(c)

Figure 3. a) SEM micrograph of the BF clay bentonite (40 000x); b) 3,6-ionene (20 000x) and c) 3,6-dodecylionene (20 000x). 
of the 3,6-ionene yielded a heterogeneous morphology, suggesting the presence of two phases: a smooth, dense phase interspersed by a slightly scaly one. In contrast, the synthesis of the 3,6-dodecylionene yielded a more lace-like homogeneous morphology.

\subsection{Fourier transform infrared spectroscopy (FTIR)}

The FTIR spectra of the samples at room temperature for bentonite and ionenes are shown in Figure 4. In these spectra, the $\mathrm{KBr}$ support showed three absorption bands at ca. 1,011-1,019 $\mathrm{cm}^{-1}$, which were not considered in the analysis. The bands at 1,624 and 1,631 $\mathrm{cm}^{-1}$ are probably associated with bound water present in the ionene, such as described in the literature for other systems ${ }^{[24]}$. Water of crystallization, for example, has been described as present in ionenes ${ }^{[19]}$. These bands observed for the complexes confirm the intercalation of ionenes interlayer spaces of bentonite. Comparatively, the spectra of pure bentonite and that incorporated with 3,6-ionene (Figure 4) showed similar

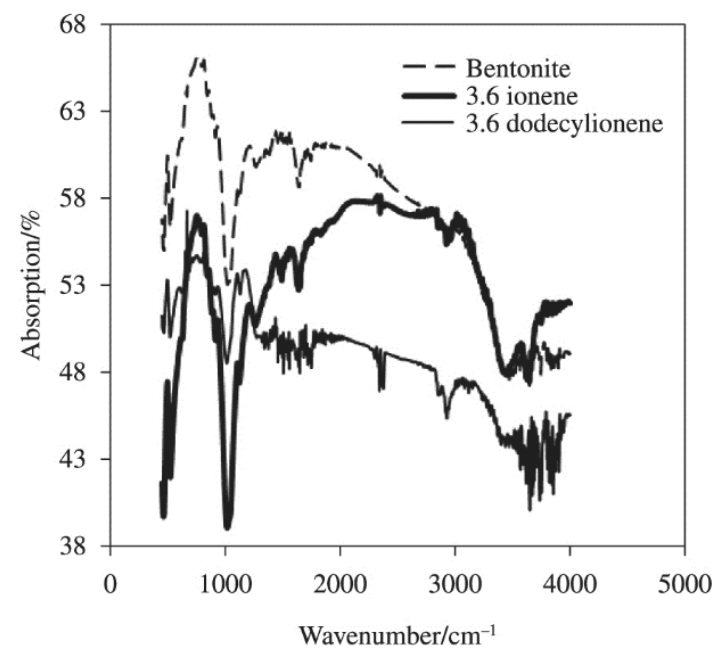

Figure 4. FTIR spectra of 3,6-ionene and 3,6-dodecylionene ${ }^{[25]}$. bands, except the band at $1,490 \mathrm{~cm}^{-1}$, which was assigned to bending vibration of $\mathrm{C}-\mathrm{N}$ group. In the 3,6-dodecylionene, significant changes to the FTIR spectra were observed. In the 3,6-dodecylionene the increase of the band at 3,649 $\mathrm{cm}^{-1}$ (O-H stretching), angular deformation of $\mathrm{CH}_{2}$ at $1,501 \mathrm{~cm}^{-1}$, and the band at $1,624 \mathrm{~cm}^{-1}$ is more evident. The 3,6-dodecyl spectrum also showed bands in $1,501 \mathrm{~cm}^{-1}$ due to the vibration of the plane symmetric angular deformation of $\mathrm{CH}_{2}$ at 2859,2929 and $3118 \mathrm{~cm}^{-1}$ due to asymmetric axial deformation of $\mathrm{CH}_{3}$ and $\mathrm{CH}_{2}$. The absorption pattern in the FTIR spectra of 3,6-dodecylionene structure appears to be associated with the aliphatic dodecyl group attached to the main chain polymer ${ }^{[25]}$.

\subsection{Thermal degradation of ionenes}

A comparison of 3,6-ionene and 3,6-dodecylionene was made at $10^{\circ} \mathrm{C} \mathrm{min}^{-1}$ up to $1,050^{\circ} \mathrm{C}$. Starting from $250{ }^{\circ} \mathrm{C}$, the organic matter began to decompose in two stages, with endothermic pyrolysis of the organic part. The endothermic event observed close to $450{ }^{\circ} \mathrm{C}$ corresponds to the energy consumed to eliminate the gaseous products generated in the first phase. The 3,6-dodecylionene loses less water than the 3,6-ionene. The results indicate that, on dry basis, 3,6-dodecyl has a higher content of organics in its structure than that of 3,6-ionene. One of the reasons why the 3,6-ionene polymer lost more mass may have been its high molecular weight. This material is more unstable due to the loss of organic matter, and this material probably remained on the outside of the polymer. Both the polymers showed two well-defined peaks in the nitrogen atmosphere. The TG/DTG curves indicate that the thermal degradation of both polymers occurred in more than one stage. Specifically, the 3,6-ionene decomposed in two stages and the 3,6-dodecylionene in three stages (Figure 5). The observed behavior in terms of the TG/DTG curves and the activation energy values suggested that the 3,6-dodecylionene $\left(\mathrm{E}=174,85 \mathrm{~kJ} \mathrm{~mol}^{-1}\right)$ is more stable thermally than the 3,6-ionene $\left(\mathrm{E}=115,52 \mathrm{~kJ} \mathrm{~mol}^{-1}\right)$ complexes. The two polymers showed different profiles in the TG/DTG curves, which is likely attributable to the structural and functional differences between 3,6-ionene

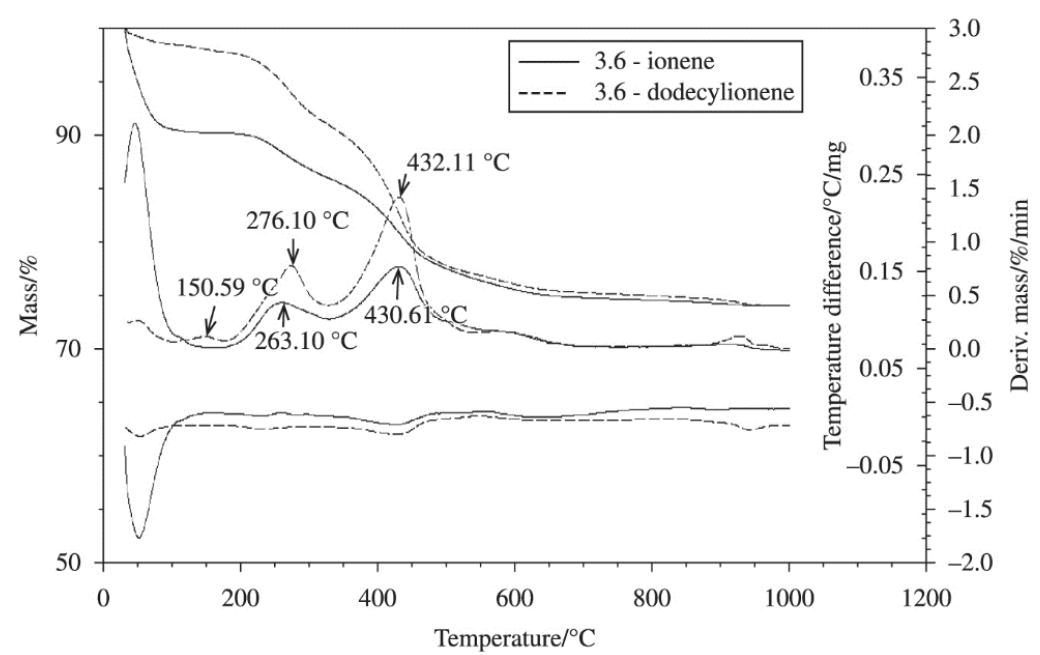

Figure 5. TG/DTG curves of 3,6-ionene and 3,6-dodecylionene measured at a heating rate of $10^{\circ} \mathrm{C} \mathrm{min}^{-1[25]}$. 
and 3,6-dodecylionene, whose configuration presents loops or tails, each containing 12 carbons ${ }^{[25]}$. The stability of the 3,6-dodecylionene may be related to its own chain, which has eleven methylene groups (- $\left.\mathrm{CH}_{2}-\right)$ and one methyl group $\left(-\mathrm{CH}_{3}\right)$. In other words, considering that each monomer of the polymer has two dodecyl chains, each monomer possesses 22 more $-\mathrm{CH}_{2}$ - groups and 2 more $-\mathrm{CH}_{3}$ groups than the 3,6-ionene. The dodecyl chain has more methyl and methylene groups than the 3,6-ionene chain.

\section{Adsorption of Benzene}

The adsorption isotherms of benzene by 3,6-ionene and 3,6-dodecylionene are shown in Figure 6. The experimental results were analyzed using the Freundlich equations and show good agreement with our experimental results.

The distribution coefficients were obtained from linear adsorption isotherms, constructed after the addition of different concentrations in batch-type experiments. The distribution coefficient $\left(\mathrm{K}_{\mathrm{d}}\right)$ was calculated by Equation 1 . The values of $\mathrm{K}_{\mathrm{d}}$ for benzene sorption by 3,6-ionene and 3,6-dodecylionene are presented in Table 2 .

$$
y=b x \rightarrow S=K_{d} C_{e} \rightarrow K_{d}=\frac{S}{C_{e}}
$$

In addition, a comparison between two ionenes showed that the 3,6-dodecylionene has a higher sorption capacity than that of the corresponding 3,6-ionene. This may be attributed to the larger number of hydrophobic segments in the interlamellar spaces, due to its structural characteristics (Figure 7). Benzene, in this case, would be incorporated into these segments through hydrophobic or van der Waals interactions. The data set reported in this research can explain the sorption mechanism of benzene onto bentonite-ionene complexes. According to the partitioning mechanism, benzene is distributed between the aqueous and solid phases of the material, according to its partition constant. The distribution coefficient $\left(\mathrm{K}_{\mathrm{d}}\right)$ approach has commonly been used to describe the sorption of hydrophobic organic compounds, or those compounds that are readily soluble in non-polar solvents, but are only sparingly soluble in water. The 3,6-dodecylionene complex was found to be strongly hydrophobic in contact with water. This behavior is due to the formation of spherical conglomerates of the polymer in water, since spheres have a smaller surface area in order to minimize their interaction with the polar medium. In this case, the partitioning of benzene would favor sorption by the copolymer, since benzene is practically insoluble in water.

\section{Conclusions}

The bentonite-ionene alternatively composed of segmented 3,6-ionene and 3,6-dodecylionene was synthesized by the polymerization of polybrene obtained from dodecyl bromide. The adsorption of the ionenes on the bentonite was confirmed by elemental analysis, X-ray fluorescence and $\mathrm{X}$-ray diffraction. All the polycations reacted to form interlayer complexes with clay, which displaced more $\mathrm{Na}^{+}$ and little $\mathrm{Ca}^{2+}$. Similarly, Br counterions were detected in association with quaternary ammonium groups non-adsorbed

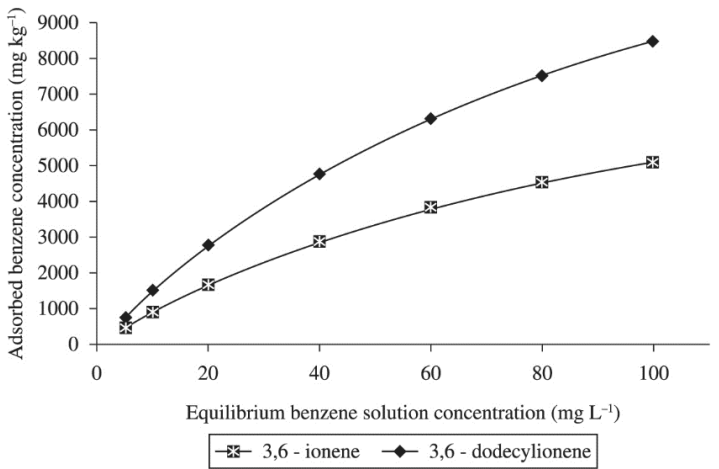

Figure 6. Adsorption of benzene by 3,6-ionene and 3,6-dodecylionene.

Table 2. Freundlich isotherm constants for benzene sorption on modified bentonite.

\begin{tabular}{lcccc}
\hline \multirow{2}{*}{ Sample } & \multicolumn{4}{c}{ Benzene } \\
\cline { 2 - 5 } & $\mathbf{K}_{\mathbf{f}}\left(\mathbf{L ~ k g}^{-1}\right)$ & $\mathbf{n}$ & $\mathbf{K}_{\mathbf{d}}\left(\mathbf{L ~ k g}^{-1}\right)$ & $\mathbf{r}^{\mathbf{2}}$ \\
\hline 3,6-ionene & 16911 & 1.240 & 12.67 & 0.983 \\
3,6-dodecylionene & 28910 & 1.051 & 71.20 & 0.982 \\
\hline
\end{tabular}

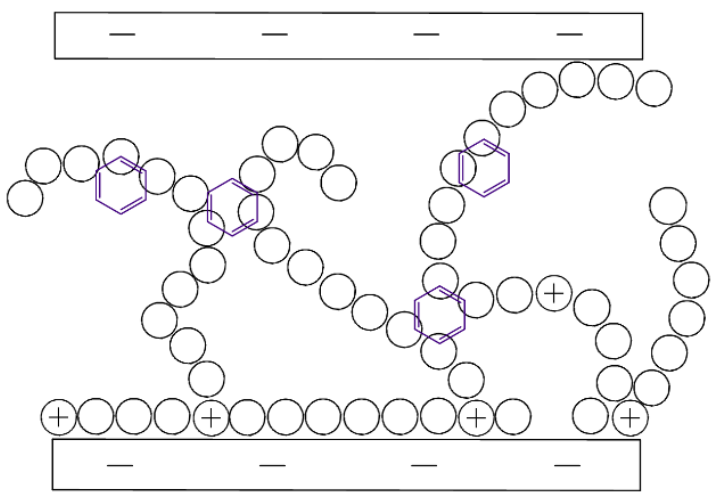

Figure 7. Conformational model for 3,6-ionene dodecyl showing a schematic representation of the benzene adsorption process through the "tails".

on the clay surface, i.e., at interlamellar sites, confirming that the cationic exchange in these systems was also satisfactory.

The intercalation of bentonite with ionene polymers caused the basal spacing of the commercial BFN bentonite to increase in from 1.5 to $3.5 \mathrm{~nm}$. The large $d_{001}$ spacing of 3,6-dodecylionene samples than that of 3,6-ionene samples was attributed to the longer tail length. Loops or chains parallel to the clay surface would cause the expansion of one alkyl chain, or $0.4 \mathrm{~nm}$ per adsorbed layer. The behavior of the TG/DTG curves and the values of activation energy suggest that 3,6-dodecylionene $\left(E=174,85 \mathrm{~kJ} \mathrm{~mol}^{-1}\right)$ is thermally more stable than 3,6 ionene $\left(E=115,52 \mathrm{~kJ} \mathrm{~mol}^{-1}\right)$ complexes.

The sorption capacity of benzene on the ionene-modified bentonite was in the order of 3,6-dodecylionene $>3,6$-ionene. From the standpoint of environmental applications, the concept of ionene-modified bentonite is a very attractive one due to its low cost of synthesis, simple experimental routine, and low processing requirements. The mechanism of adsorption 
suggests a direct interaction with the dodecyl chain containing 12 carbons, which are present in 3,6-dodecylionene but not in 3,6-ionene. The value of the distribution coefficient $\left(\mathrm{K}_{\mathrm{d}}\right)$ adopted for 3,6-dodecylionene was $71.20 \mathrm{~L} \mathrm{~kg}^{-1}$.

\section{Acknowledgements}

This research was financed by the São Paulo State Research Foundation - FAPESP (grant 2010/01287-3). The authors acknowledge the National Institute of Science and Technology for Environmental Studies (INCT-CEPEMA/ USP), Department of Chemical Engineering (EPUSP) and BF-Clay Especialidades Ltda.

\section{References}

1. Rembaum, A., Baumgartner, W., \& Eisenberg, A. (1968). Aliphatic ionenes. Journal of Polymer Science. Part B: Polymer Letters, 6(3), 159-171. http://dx.doi.org/10.1002/ pol.1968.110060302.

2. Darley, H. C. H., \& Gray, G. R. (1988). Composition and properties of drilling and completion fluids (5th ed.). Texas: Gulf Publishing Company.

3. Ross, C. S., \& Shannon, E. V. (1926). Minerals of bentonite and related clays and their physical properties. Journal of the American Ceramic Society, 9(2), 77-96. http://dx.doi. org/10.1111/j.1151-2916.1926.tb18305.x.

4. Paiva, L. B., Morales, A. R., \& Díaz, F. R. V. (2008). Organoclays: Properties, preparation and applications. Applied Clay Science, 42(1-2), 8-24. http://dx.doi.org/10.1016/j.clay.2008.02.006.

5. Dentel, S. K., Bottero, J. Y., Khatib, K., Demougeot, H., Duguet, J. P., \& Anselme, C. (1995). Sorption of tannic acid, phenol and. 2,4,5 trichlorophenol on organoclays. Water Research, 29(5), 1273-1280. http://dx.doi.org/10.1016/0043-1354(94)00277-E.

6. Smith, J. A., \& Galan, A. (1995). Sorption of nonionic organic contaminants to single and dual organic cation bentonites from water. Environmental Science \& Technology, 29(3), 685-692. http://dx.doi.org/10.1021/es00003a016. PMid:22200277

7. Springman, K., Mayura, K., McDonald, T., Donnelly, K. C., Kubena, L. F., \& Phillips, T. D. (1999). Organoclay adsorption of wood-preserving waste from groundwater. Analytical and toxicological evaluations. Toxicological and Environmental Chemistry, 71(1-2), 247-259. http://dx.doi. org/10.1080/02772249909358796.

8. Alther, G. (2002). Using organoclays to enhance carbon filtration. Waste Management, 22(5), 507-513. http://dx.doi. org/10.1016/S0956-053X(01)00045-9. PMid:12092760

9. Koh, S., \& Dixon, J. B. (2001). Preparation and application of organominerals as sorbents of phenol, benzene and toluene. Applied Clay Science, 18(3-4), 111-122. http://dx.doi. org/10.1016/S0169-1317(00)00040-5.

10. Rodriguez-Sarmiento, D. C., \& Pinzón-Bello, J. A. (2001). Adsorption of sodium dodecylbenzene sulfonate on organophilic bentonites. Applied Clay Science, 18(3-4), 173-181. http:// dx.doi.org/10.1016/S0169-1317(00)00022-3.

11. Lee, S. Y., \& Kim, S. J. (2002). Adsorption of naphthalene by HDTMA modified kaolinite and halloysite. Applied Clay Science, 22(1-2), 55-63. http://dx.doi.org/10.1016/S01691317(02)00113-8.

12. Redding, A. Z., Burns, S. E., Upson, R. T., \& Anderson, E. F. (2002). Organoclay sorption of benzene as a function of total organic carbon content. Journal of Colloid and Interface Science, 250(1), 261-264. http://dx.doi.org/10.1006/jcis.2001.8205. PMid:16290659
13. Barker, J. F., Hubbard, C. E., Lemon, L. A., \& Vooro, K. A. (1992). The influence of methanol in gasoline fuels on the formation of dissolved plumes, and the fate and natural remediation of methanol and BTEX dissolved in groundwater. In P. T. Kostecki \& E. J. Calabrese (Eds.), Hydrocarbon contaminated soils and groundwater (pp. 264-273). New York: Lewis Publishers.

14. Corseuil, H. X., Monier, A. L., Fernandes, M., Schneider, M. R., Nunes, C. C., do Rosario, M., \& Alvarez, P. J. J. (2011). BTEX plume dynamics following an ethanol blend release: geochemical footprint and thermodynamic constraints on natural attenuation. Environmental Science \& Technology, 45(8), 3422-3429. http://dx.doi.org/10.1021/es104055q. PMid:21410252

15. Campos, V., Souto, L. S., Medeiros, T. A. M., Toledo, S. P., Sayeg, I. J., Ramos, R. L., \& Shinzato, M. C. (2014). Assessment of the removal capacity, tolerance, and anatomical adaptation of different plant species to benzene contamination. Water, Air, and Soil Pollution, 225(8), 2033-2045. http://dx.doi. org/10.1007/s11270-014-2033-7.

16. Kissinger, H. E. (1957). Reaction kinetics in differential thermal analysis. Analytical Chemistry, 29(11), 1702-1706. http://dx.doi.org/10.1021/ac60131a045.

17. Ghiaci, M., Kia, R., \& Kalbasi, R. J. (2004). Investigation of thermodynamic parameters of cetyl pyridinium bromide sorption onto ZSM-5 and natural clinoptilolite. The Journal of Chemical Thermodynamics, 36(2), 95-100. http://dx.doi. org/10.1016/j.jct.2003.09.002.

18. Hagi, H., Ooishi, O., \& Tanaka, R. (1979). Polymeric amines and ammonium salts. In Proceedings of the International Symposium on Polymeric Amines and Ammonium Salts. New York: Pergamon Press.

19. Soldi, V., Erismann, N. M., \& Quina, F. H. (1988). Micellemimetic ionene polyelectrolytes. Journal of the American Chemical Society, 110(15), 5137-5143. http://dx.doi.org/10.1021/ ja00223a037.

20. Tcacenco, C. M., \& Quina, F. H. (2007). Fusion-fission transport of probes and quenchers in microdomains of an amphiphilic ionene polyelectrolyte. Photochemistry and Photobiology, 83(3), 542-546. http://dx.doi.org/10.1562/2006-09-09-RA-1036. PMid: 17576370

21. Breen, C. (1999). The characterisation and use of polycationexchanged bentonites. Applied Clay Science, 15(1-2), 187-219. http://dx.doi.org/10.1016/S0169-1317(99)00024-1.

22. Costa Filho, A. P., Gomes, A. S., \& Lucas, E. F. (2005). Preparação e caracterização de organobentonita modificada com ionenos alifáticos. Polímeros: Ciência e Tecnologia, 15(3), 212-217. http://dx.doi.org/10.1590/S0104-14282005000300012.

23. Churchman, G. L. (2002). Formation of complexes between bentonite and different cationic polyelectrolytes and their use as sorbents for non-ionic and anionic pollutants. Applied Clay Science, 21(3-4), 177-189. http://dx.doi.org/10.1016/ S0169-1317(01)00099-0.

24. Fang, J. M., Fowler, P. A., Tomkinson, J., \& Hill, C. A. S. (2002). The preparation and characterisation of a series of chemically modified potato starches. Carbohydrate Polymers, 47(3), 245252. http://dx.doi.org/10.1016/S0144-8617(01)00187-4.

25. Campos, V., Dweck, J., Nascimento, C. A. O., \& Tcacenco, C. M. (2013). Thermal stability of ionene polymers. Journal of Thermal Analysis and Calorimetry, 112(3), 1221-1229. http:// dx.doi.org/10.1007/s10973-012-2694-7.

Received: Apr. 17, 2014

Revised: July 17, 2014

Accepted: Sept. 09, 2014 